\title{
Design of efficient photocatalytic processes for the production of hydrogen from biomass derived substrates
}

\author{
Gianguido Ramis ${ }^{1}$, Elnaz Bahadori ${ }^{2}$ and Ilenia Rossetti ${ }^{*}$
}

${ }^{1}$ DICCA, Università degli Studi di Genova and INSTM Unit-Genova, via All'Opera Pia 15A, Genoa, Italy

${ }^{2}$ Chemical Plants and Industrial Chemistry Group, Dip. Chimica, Università degli Studi di Milano, CNR-ISTM and INSTM Unit Milano-Università, via C. Golgi 19, 20133 Milano, Italy.

\begin{abstract}
The photoreforming of glucose has been studied over $\mathrm{TiO}_{2}$ photocatalyst with different photoreactors, focusing on the effect of the reaction conditions: temperature, pressure, catalyst and substrate concentration. The effect of pressure was particularly significant, decreasing hydrogen evolution rate, but improving the conversion of the substrate. Furthermore, pressure moderately higher than ambient allowed to operate at high temperature $\left(80^{\circ} \mathrm{C}\right)$, boosting hydrogen productivity. Most experiments were carried out on glucose photoreforming, but, for the first time, the photoconversion of levulinic acid was investigated, as an interesting product of biomass hydrolysis under harsh conditions. Levulinic acid led to the production of ethane and ethylene in gas phase, interpreted according to a preliminary hypothesis of the photoconversion mechanism. High hydrogen productivity was achieved, in most cases higher than the literature benchmark.
\end{abstract}

\footnotetext{
*Corresponding author: fax +390250314059; email ilenia.rossetti@unimi.it
} 
Keywords: Photoreforming; Photocatalytic hydrogen production; High pressure photocatalysis; Glucose; Photocatalytic processes.

\section{1 - Introduction}

Photocatalytic processes for hydrogen production gained considerable attention in the last two decades, as a virtuous way to exploit solar energy for the production of a clean energy vector [1-4]. Despite this growing interest, however, solar driven water splitting is still far from application due to very low productivity. Indeed, the energy to be supplied due to thermodynamic reasons, summed to overpotentials, render very hard the exploitation of a true solar driven device. A target productivity of $2-3 \mathrm{~mol} / \mathrm{min} \mathrm{kg}_{\text {cat }}$ has been set to attract industrial interest [5].

The mechanism of the photocatalytic reaction prescribes two half reactions, promoted by a semiconductor. The latter absorbs photons with energy higher than its band gap, promoting an electron from the valence to the conduction band. This electron is responsible of the hydrogen evolution reaction, i.e. $\mathrm{H}^{+}+\mathrm{e}^{-} \rightarrow 0.5 \mathrm{H}_{2}$. In order to close the circuit, the electron vacancy $\left(\right.$ hole, $\mathrm{h}^{+}$) remaining in the valence band should be reduced thanks to an electron donor present in the reaction environment. In direct water photosplitting, the electron donor is water itself, leading to oxygen evolution. However, this step is the rate limiting one, since it is very slow due to the simultaneous need of a 4-electrons transfer and thus it requires high potential. Furthermore, the co-presence of $\mathrm{H}_{2}$ and $\mathrm{O}_{2}$ as products in the same environment should be avoided by designing separate reaction cells, with a separation membrane that adds further losses [6].

In order to improve the feasibility of the process the research was focused on alternative electron donors, also called hole scavengers, which are more easily oxidised than water. 
The first experiments were carried out on very simple organic molecules, such as methanol or formic acid [4,7-11], confirming a significant increase of the hydrogen production rate. Later, renewable biomass derived compounds were investigated, such as ethanol and glycerol $[1,3,10,12-14]$, or, more recently, glucose and other mono- or oligo-saccharides [15-26]. Few examples of direct photoreforming of cellulose or raw biomass have been also attempted, but with much lower hydrogen productivity with respect to simpler molecules [2729].

Kuehnel and Reisner [30] reviewed recent advances in the photoreforming of biomass derived compounds, which is much more energy favourable since the oxidation reaction is less demanding than oxygen formation from the thermodynamic point of view, besides the already mentioned kinetic aspects.

$$
\begin{gathered}
\mathrm{C}_{6} \mathrm{H}_{12} \mathrm{O}_{6}+6 \mathrm{H}_{2} \mathrm{O} \rightarrow 12 \mathrm{H}_{2}+6 \mathrm{CO}_{2} \quad\left(\Delta \mathrm{E}^{\circ}=+0.001 \mathrm{~V}\right) \\
\mathrm{H}_{2} \mathrm{O} \rightarrow \mathrm{H}_{2}+0.5 \mathrm{O}_{2} \quad\left(\Delta \mathrm{E}^{\circ}=-1.23 \mathrm{~V}\right)
\end{gathered}
$$

Therefore, the energy adsorbed is just needed to overcome the activation barriers, ideally making the process feasible also under visible light irradiation. Various examples of monosaccharides are reported, which induce variable results based on their ability to adsorb on the catalyst surface and intrinsic reactivity.

G. Balducci [31] carried out a theoretical study on the modes of glucose adsorption on the surface of titania, showing that the molecular adsorption mode is favoured with respect to the bridged one. The reaction rate would follow a Langmuir type mechanism, depending on the concentration of adsorbed glucose rather than on its amount in solution [19,31]. Furthermore, by considering the density of states, there are different surface adsorption modes through which the glucose molecule can act as hole scavenger for $\mathrm{TiO}_{2}$. 
Furthermore, di-saccharides are reviewed [30] which suffer of kinetic limitations with respect to monomers. Examples of cellulose PR are also reported [19,30], with even higher limitations due to the compact ternary structure of the substrate. Lignin and raw biomass have limited application potential and yield due to scarce solubility, light scattering and absorption from coloured substances. Aquatic plants gave higher hydrogen yields with respect to terrestrial ones due to their lower lignin content [30]. Swine sewage has been also tested [32] under different irradiation sources, but, again, with limited hydrogen productivity. lervolino et al. [15] tested real waste solutions, such as cherries washing one, obtaining interesting results, but with a different approach based on the photo-Fenton reaction.

Regarding the mechanism of PR, the hydrogen evolution reaction is faster, independent of the substrate and is believed to occur through the hydrogen ions coming from water rather than from the biomass. The biomass oxidation reaction instead involves the direct hole transfer to the molecule adsorbed rather than the oxidation mediated by the $\mathrm{OH}$. radicals possibly forming in solution. The molecule degradation occurs by elimination of $\mathrm{C} 1$ fragments, mainly as formic acid $[25,26,30,33,34]$. In some cases, intermediate steps of glucose isomerisation to fructose (linear and cyclic) are reported [35]. Other researchers observed hydrogen formation only in presence of Pt under anaerobic conditions [26] and in presence of alpha hydrogen in the substrate. They also support the progressive elimination of formic acid moieties.

The need of hydrogen in alpha position to allow the alpha-scission and formic acid formation is supported also by Chong et al. [33]. The same mechanism is reported for polyalcohols, for which the primary step is the terminal oxidation. A metal co-catalyst is needed, but it does not influence selectivity. Interestingly, the reaction is also studied with $\mathrm{H}_{2}$ production together with intermediates of oxidation with higher added value, to improve the economic sustainability of the reaction [33], such as gluconic acid, xylitol and arabinose [36]. 
To the best of our knowledge, no investigation was carried out on different possible biomass hydrolysis solutions, e.g. levulinic acid and formic acid, which are co-produced when performing the hydrolysis under harsher conditions, leading to lower humines concentration (more stable hydrolysed solution) and an easily separable product.

According to these examples, some considerations appear evident. If on one hand the photoreforming of glucose seems promising, in all the examined cases the reactors were very small (mostly smaller than $100 \mathrm{ml}$ ), often with very high irradiation power, with no strict control in power distribution in the reactor. If this is reasonable in such small devices, it prevents any attempt to scale up. Furthermore, very diluted glucose solutions (usually maximum $1 \mathrm{~g} / \mathrm{L}$ ) are used. This is incompatible with current technologies for the hydrolysis of biomass, which usually allow much more concentrated products (15 to 30 times), which ideally should be reformed without dilution for a better volumetric efficiency of the plant. Moreover, very scarce attention is paid to the optimisation of reaction conditions. Most reports check the effect of catalyst concentration, but only a few investigate the effect of temperature, which turns out to be very important. Indeed, increasing hydrogen productivity is reported up to $50-70^{\circ} \mathrm{C}[25,28]$, attributed to a speed up of the "dark" reaction steps (adsorption/desorption, diffusion, etc.).

No attention at all is instead paid to pressure. In the recent past we have developed a unique photoreactor for the photoreduction of $\mathrm{CO}_{2}$ able to operate up to 20 bar [37-42]. Even if an increase of pressure is not expected to favour directly the photoreforming, since it is a gas evolution reaction, occurring through an increase of the number of moles, this reactor allows the exploration of unconventional reaction conditions, e.g. by increasing the reaction temperature above the limits imposed by ambient pressure operation.

Therefore, in this work, we have investigated the photoreforming of glucose trying to optimise the operating conditions (pressure, temperature, catalyst and glucose concentration) in two types of photoreactors, both with an immersion lamp with a strict 
control of light distribution, and characterised by different volume (ca. $300 \mathrm{~mL}$ and $1.3 \mathrm{~L}$ ). The photoreforming of levulinic acid and of a 1:1 mixture of levulinic and formic acid was also reported here for the first time.

\section{2 - Experimental}

\section{Catalyst preparation and characterisation}

Pure $\mathrm{TiO}_{2}$ sample has been used as a commercial benchmark supplied by Evonik, P25 sample.

Different metals were added by wet impregnation from the following precursors with a fixed metal loading of $0.1 \mathrm{~mol} \%$, followed by reduction at the specified temperature for $1 \mathrm{~h}$. $\mathrm{Pt}$ from $\mathrm{Pt}(\mathrm{II})$ acetylacetonate (Sigma Aldrich, purity $97 \%$ ), reduced at $700^{\circ} \mathrm{C}$; $\mathrm{Au}$ from $\mathrm{Au}(\mathrm{III})$ chloride (Sigma Aldrich, purity $99 \%$ ), reduced at $700^{\circ} \mathrm{C}$; Pd from $\mathrm{Pd}(\mathrm{II})$ nitrate dihydrate (Sigma Aldrich, $40 \% \mathrm{Pd}$ content), reduced at $300^{\circ} \mathrm{C}$; $\mathrm{Ag}$ from $\mathrm{Ag}(\mathrm{I})$ nitrate (Sigma Aldrich, purity $99 \%)$, reduced at $150^{\circ} \mathrm{C}$.

The specific surface area of the sample was determined by $\mathrm{N}_{2}$ adsorption/desorption at $77 \mathrm{~K}$ with a Micromeritics (ASAP2020) apparatus. The data were elaborated through the BET algorithm to get the specific surface are and according to the BJH one for the porosity contribution. The portion of micropores was assessed through the t-plot method.

The crystal phases were determined by X-ray diffraction (Philips 3020) at room temperature by using the CuKa radiation $(\lambda=1.5406 \AA)$. Intensities were collected over a $21^{\circ}-90^{\circ} 2 \theta$ range with $0.03^{\circ}$ step size and $4 \mathrm{~s}$ step time. The apparatus was provided with graphite monochromator. The voltage and current intensity of the generator were set at $40 \mathrm{kV}$ and $30 \mathrm{~mA}$ respectively. The raw data were compared with JCPDS files. 
Diffuse Reflectance (DR) UV-Vis spectra of samples were measured on a Cary 5000 UVVis-NIR spectrophotometer (Varian instruments) in the range of $200-800 \mathrm{~nm}$.

\section{Photocatalytic testing}

The innovative high pressure photoreactor used for activity testing has been described in detail elsewhere $[39,41,42]$. It is made of AISI 316 stainless steel with an axial UVA lamp (medium-pressure $\mathrm{Hg}$ vapour lamp with a range of emission wavelengths from $254 \mathrm{~nm}$ to $364 \mathrm{~nm}$, nominal power $125 \mathrm{~W}$ ) and a magnetic stirrer ensures proper liquid mixing. The internal capacity is ca. 1.3 L, filled with ca. $1.2 \mathrm{~L}$ solution. The temperature is kept constant through a double-walled thermostatic system.

The emitted power was periodically measured by means of a photo-radiometer (Delta OHM HD2102,2) at $315-400 \mathrm{~nm}$. The harmful overheating of the lamp bulb was avoided thanks to an air circulation system, which in turn determined the power of the source. A compromise between the high irradiation power and high lamp lifetime was chosen and corresponded to $0-1,000 \mathrm{~L} \mathrm{~h}^{-1}$ cooling air flow, with periodic systematic mapping of the irradiance every 3-4 tests. Details on the radiation modelling through the reactor can be found elsewhere [43]. The catalyst (variable amounts) has been suspended in $1.2 \mathrm{~L}$ of demineralized and outgassed water and added with glucose, levulinic acid, formic acid or a mixture of them in proper concentration. Testing was carried out typically for $5 \mathrm{~h}$. Variable pressure (2-6 bar) and temperature $\left(20-80^{\circ} \mathrm{C}\right)$ were tested. The temperature was controlled thanks to a thermosetting bath with circulating fluid and showed approximately the same under dark conditions.

A second photoreactor was tested, with the same configuration and approximately the same length to diameter ratio (geometric factor) and an axial immersion lamp (UVA, $75 \mathrm{~W}$ ). The

total volume was however ca. 1 order of magnitude smaller to check the effect of the distance from the source on activity and of the overall irradiance. 


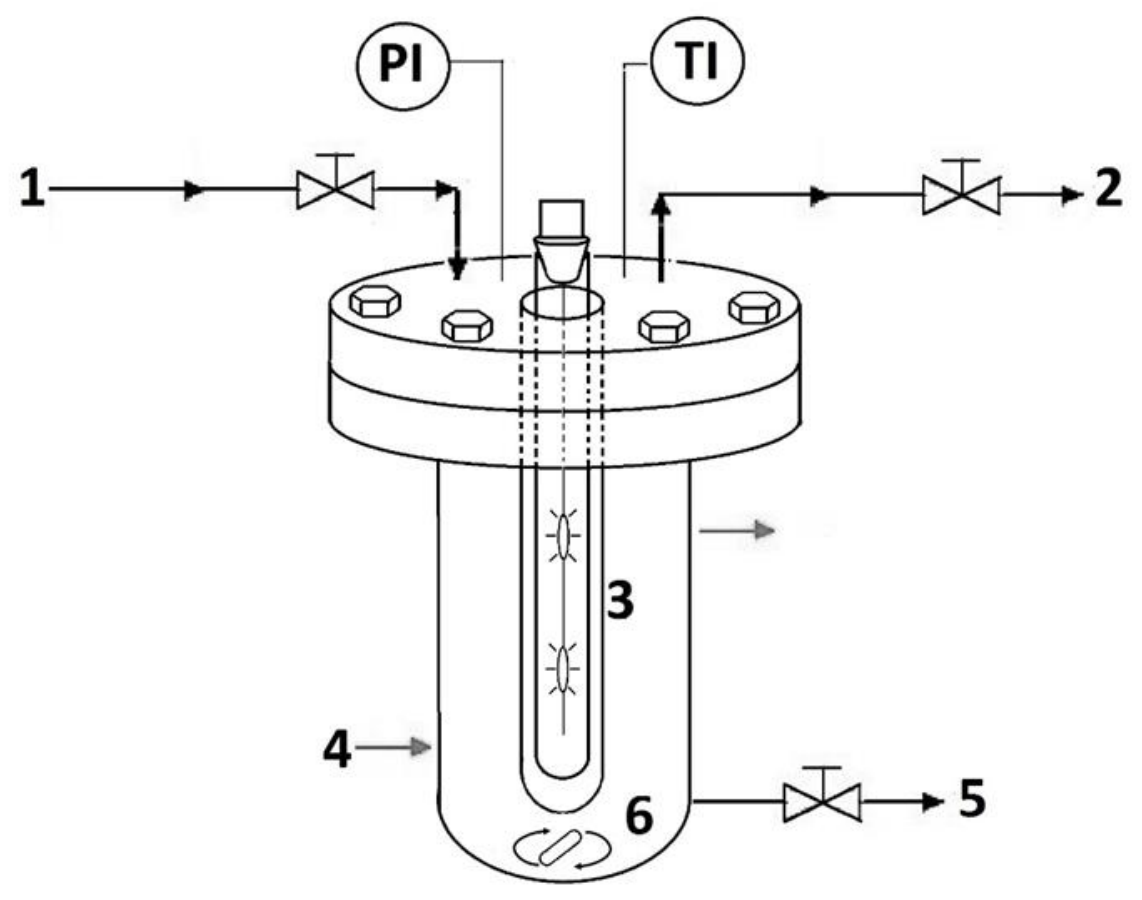

Figure 1. Sketch of the High Pressure Photoreactor. 1: Pressure Reducer, 2: Sample Valve for Gas Phase, 3: Lamp, 4: Double-walled Thermostatic System, 5: Sample Valve for Liquid Phase, 6: Magnetic Stirrer. PI: Pressure Indicator; TI: Temperature Indicator. Reproduced from [38] by kind permission of Elsevier.

For both reactors, after the reaction, the liquid mixture has been analysed by means of Total Organic Carbon (TOC) analysis, carried out by chemical titration by potassium dichromate, according to the ISO 14235:1998 method. The gas phase was sampled every hour from the headspace of the photoreactor and analysed by a gas chromatograph (Agilent 7890) equipped with HP Plot Q and MS columns and a TCD detector. The set up was proper for the quantification of $\mathrm{H}_{2}, \mathrm{CO}, \mathrm{CO}_{2}, \mathrm{CH}_{4}$ and polar/non polar light gases. The maximum experimental error on $\mathrm{H}_{2}$ productivity (based on 5 reproducibility tests) was $\pm 7.3 \%$, while on TOC analysis was $10.2 \%$. The latter was attained at the highest conversion, where the compounds to be determined were much more heterogeneous leading to higher error. 


\section{3 - Results and discussion}

\section{1 - Catalyst properties}

We have selected the simplest photocatalyst formulation, a well established benchmark, to make a comparative screening of the operating conditions and of the photoreactor size. Therefore, $\mathrm{TiO}_{2} \mathrm{P} 25$ was used as a cheap, commercial, abundant and photo-resistant material. This sample was characterised by a mixture of two polymorphs of $\mathrm{TiO}_{2}$, anatase (ca. 78\%) and rutile (ca. 22\%). The co-presence of the two phases has been described as an important feature to achieve efficient charge separation, thus inhibiting the electron-hole recombination, with respect to pure phases. The surface area of the sample was $45 \mathrm{~m}^{2} / \mathrm{g}$, with total pore volume $0.12 \mathrm{~cm}^{3} / \mathrm{g}$ and $\mathrm{ca} .15 \%$ contribution of micropores, the remaining being mesopores [45]. The sample band gap was measured by DR-UV-Vis spectroscopy and was $3.36 \mathrm{eV}$.

After selection of the best operating conditions we also explore the effect of metals addition to titania. Metals with appropriate workfunction can act as electron sinks, thus preventing their recombination with the holes. Furthermore, some metals can improve visible light harvesting through plasmon resonance effects. In this work, we have compared some noble metals added by impregnation and reduced.

The XRD patterns of the metal-promoted samples are reported in Figure 2 and reveal a substantially unmodified structure with respect to bare P25. Indeed, it both anatase and rutile phases are present, as referred to the standard JCPDS database (anatase: file 84-1286; rutile: file $88-1175)$. Thus, the addition of 0.1 mol\% metal did not affect the crystalline structure of titania, except a slight increase of the anatase/rutile ratio. The crystal size was determined through the Scherrer equation and was ranging between 15 and $21 \mathrm{~nm}$, 
increasing for the metal-loaded samples with respect to bare P25 due to the thermal treatment for the reduction of the metal precursor.

The $\mathrm{N}_{2}$ adsorption/desorption isotherms are reported in Figure 3 , which reveals a substantially not porous material. The specific surface area of the different samples is reported in Table 1.

The UV-Vis absorption spectra (Figure 4) have been recorded to estimate the band gap energy from the plot of $(\mathrm{hv \alpha})^{1 / 2}$ versus photon energy (hv). The intercept of the tangent to the plot will give a good approximation of the indirect band gap energy for $\mathrm{TiO}_{2}$ and its relative metals-added samples [46]. The calculated band gap is reported in Table 1.

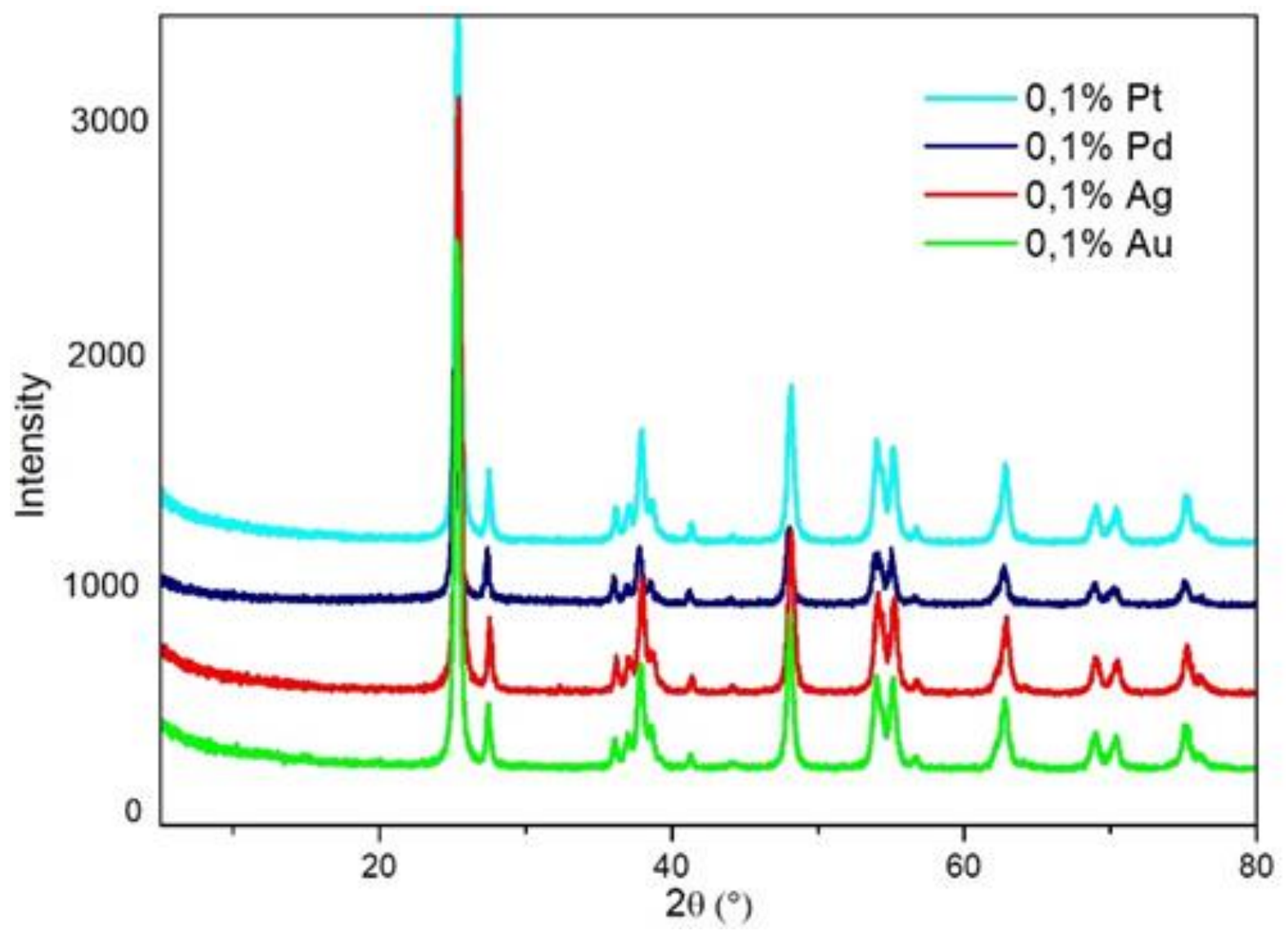

Figure 2: XRD patterns of metal-promoted catalysts. 


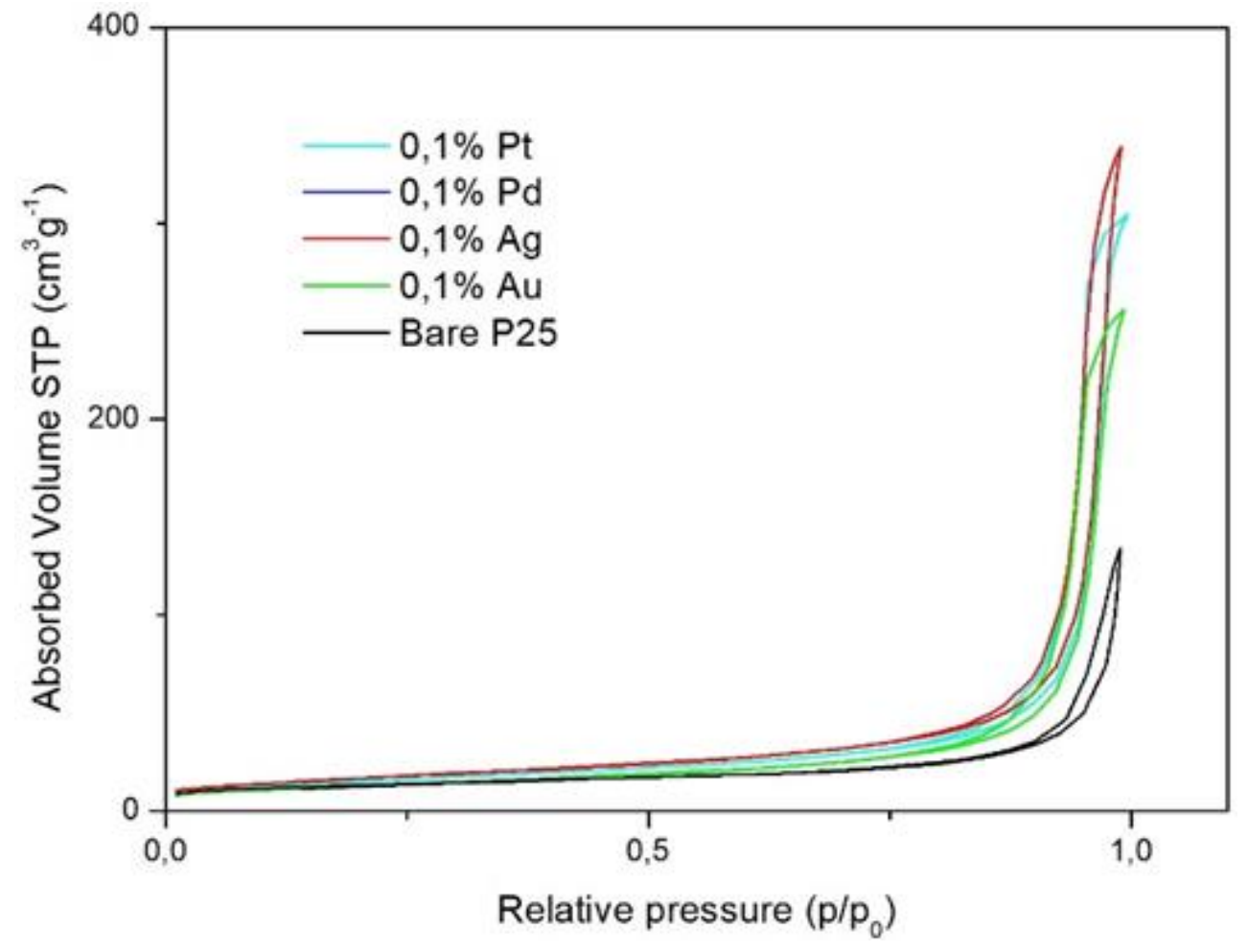

Figure 3: $\mathrm{N}_{2}$ adsorption/desorption isotherms of the catalysts.

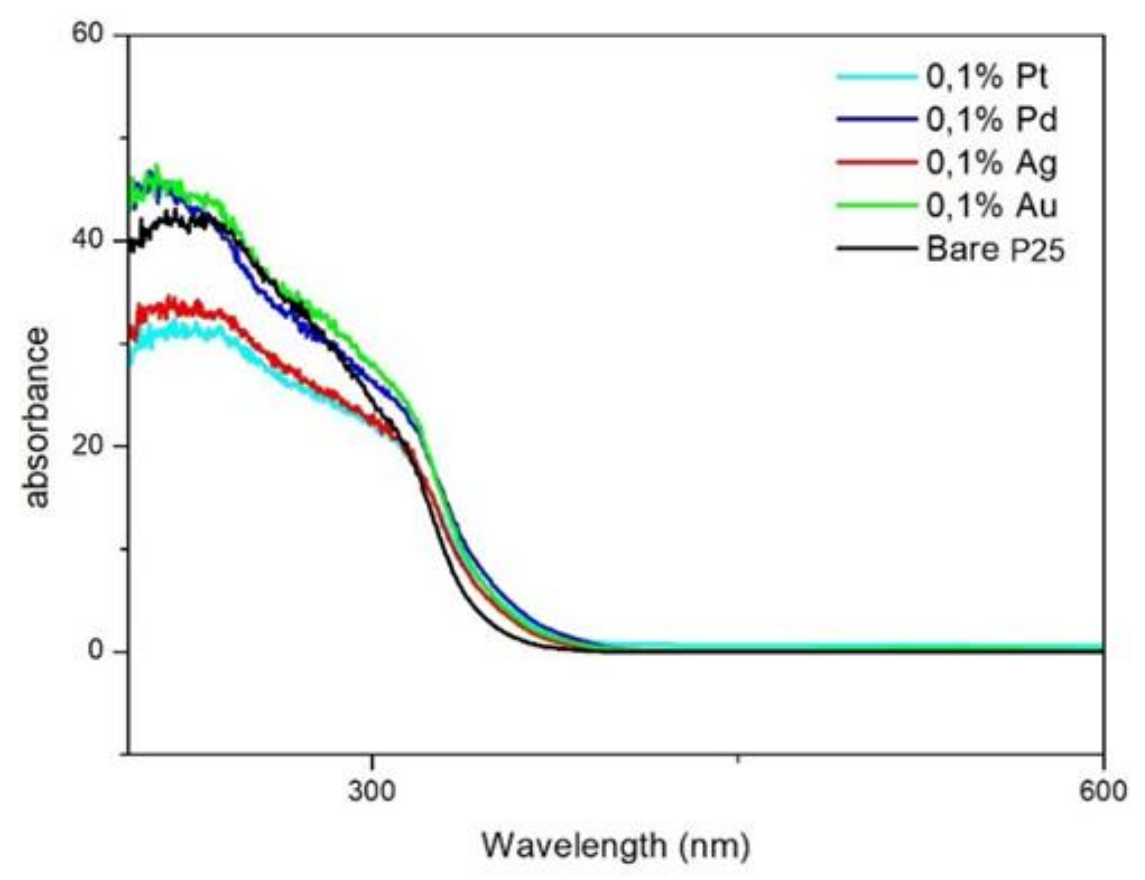

Figure 4: DR-UV-Vis spectra of the photocatalysts. 


\begin{tabular}{llllll}
\hline Sample & P25 & Au/P25 & Ag/P25 & Pd/P25 & Pt/P25 \\
\hline Anatase / Rutile (\%) & $78 / 22$ & $87 / 13$ & $87 / 13$ & $81 / 19$ & $87 / 13$ \\
\hline Crystallite size (nm) & 15 & 21 & 21 & 20 & 21 \\
\hline BET Surface area ( $\left.\mathbf{m}^{2} \mathbf{g}^{-1}\right)$ & $45.0 \pm 0.1$ & $47.3 \pm 0.8$ & $61.2 \pm 0.6$ & $57.0 \pm 0.2$ & $55.1 \pm 0.2$ \\
& & & & & \\
\hline Band Gap energy (eV) & 3.41 & 3.27 & 3.23 & 3.18 & 3.12 \\
\hline
\end{tabular}

Table 1: Main features of the selected photocatalysts. Cristallite size determined by the Scherrer equation.

\section{2 - Photoreforming of carbohydrates}

\section{Blank tests}

Various blank tests have been carried out to exclude spurious effects.

In absence of photocatalyst and glucose, no hydrogen was detected. When adding the photocatalyst and glucose under dark conditions, very limited glucose amount was missing from the carbon balance, due to adsorption on the catalyst. Indeed, the mass balance has been confirmed after reaction by thermogravimetry on the recovered catalyst.

In presence of photocatalyst and in absence of sugar the amount of hydrogen detected was negligible, due to the very limited contribution of water splitting. This also rules out the effect of possible carbon-based impurities present in the sample, possibly acting as hole scavengers.

The effect of $\mathrm{pH}$ for this reaction has been already studied [47] and turned out to affect for ca. $10 \%$ the hydrogen productivity. The best results were achieved around neutral conditions, overall matching the point of zero charge (PZC) of the semiconductor. The 
present $\mathrm{TiO}_{2}$ sample was characterised by a $\mathrm{PZC} \cong 6.25$, so the native $\mathrm{pH}$ of the aqueous glucose solution $(\mathrm{pH}=5.5)$ was maintained ensuring a slightly positive charged surface.

Afterwards we have investigated the effect of the different process variables on hydrogen productivity and organics conversion. We have singly varied each parameter in the experimental range applicable. Then the optimized parameters were kept fixed at the best value for further screening. The commercial P25 benchmark photocatalyst has been employed for all these preliminary screening and relative reproducibility analysis, in order to have a sufficient amount of identical sample. The further exploration of catalyst formulation and substrate type was performed on the previously optimized conditions.

\section{Effect of reactor pressure}

The effect of pressure has almost never been investigated in photocatalysis due to the typical use of quartz or glass devices. Thanks to the high pressure photoreactor developed we were able to assess the effect of this parameter (Fig. 2).

\begin{tabular}{|c|c|c|c|c|c|c|c|}
\hline $\begin{array}{l}\text { Test } \\
\#\end{array}$ & $\begin{array}{l}\text { Co- } \\
\text { catalyst }\end{array}$ & $\begin{array}{l}\mathbf{P} \\
\text { (bar) }\end{array}$ & $\begin{array}{l}\text { T } \\
\text { ( } \mathbf{C} \text { C) }\end{array}$ & $\begin{array}{l}\text { Glucose } \\
\text { concentration } \\
\text { (g/L) }\end{array}$ & $\begin{array}{l}\text { Catalyst } \\
\text { concentration } \\
\text { (g/L) }\end{array}$ & $\begin{array}{l}\mathbf{H}_{\mathbf{2}} \text { productivity } \\
\text { (mol/h kgcat) }\end{array}$ & $\begin{array}{l}\text { C Conversion } \\
\text { (\%) }\end{array}$ \\
\hline $\mathbf{1}$ & - & 2 & 80 & 5 & 1 & 0.649 & 12.9 \\
\hline $\mathbf{2}$ & - & 4 & 80 & 5 & 1 & 0.333 & 35.1 \\
\hline $\mathbf{3}$ & - & 6 & 80 & 5 & 1 & 0.141 & $/$ \\
\hline $\mathbf{4}$ & - & 2 & 80 & 5 & 0.25 & 2.098 & 15.1 \\
\hline $\mathbf{5}$ & - & 4 & 80 & 5 & 0.25 & 1.910 & 20.3 \\
\hline $\mathbf{6}$ & - & 4 & 20 & 5 & 1 & 0 & 0 \\
\hline $\mathbf{7}$ & - & 4 & 40 & 5 & 1 & 0.029 & $/$ \\
\hline $\mathbf{8}$ & - & 4 & 60 & 5 & 1 & 0.015 & 51.3 \\
\hline $\mathbf{9}$ & - & 4 & 80 & 15 & 0.25 & 0.587 & 2.4 \\
\hline $\mathbf{1 0}$ & - & 4 & 80 & 5 & 0.5 & 0.449 & 12.0 \\
\hline $\mathbf{1 1}$ & - & 4 & 80 & 5 & 0.125 & 2.934 & 27.0 \\
\hline $\mathbf{1 2}$ & - & 4 & 80 & 5 & 0.0625 & 6.603 & 21.8 \\
\hline $\mathbf{1 3}$ & $\mathrm{Pt}$ & 4 & 80 & 5 & 0.25 & 14.69 & 25.7 \\
\hline $\mathbf{1 4}$ & $\mathrm{Au}$ & 4 & 80 & 5 & 0.25 & 10.68 & 28.5 \\
\hline
\end{tabular}




\begin{tabular}{|c|c|c|c|c|c|c|c|}
\hline 15 & $\mathrm{Ag}$ & 4 & 80 & 5 & 0.25 & 4.64 & 10.0 \\
\hline $\mathbf{1 6}$ & $\mathrm{Pd}$ & 4 & 80 & 5 & 0.25 & 9.76 & $/$ \\
\hline
\end{tabular}

Table 2: Results of activity testing under variable conditions for catalyst P25. Metal loading 0.1 mol\%. Conversion measured after $5 \mathrm{~h}$. Maximum experimental error on $\mathrm{H}_{2}$ productivity $= \pm 7.3 \%$, on $\mathrm{C}$ conversion $=10.2 \%$.

Tests 1-3 were carried out at increasing pressure. The $\mathrm{H}_{2}$ productivity decreased steadily with growing pressure, due to thermodynamic inhibition of the photoreforming reaction, which occurs with increasing number of moles. Identical trend was obtained at different catalyst concentration, i.e. 0.25 (Tests 4-5) or $1 \mathrm{~g} / \mathrm{L}$. However, the conversion of the organic carbon in liquid phase increased steeply with reactor pressure, likely thanks to more favourable adsorption of the reactant on the catalyst surface. Indeed, the increase of conversion was much more pronounced (from 12 to $35 \%$ when passing from 2 to 4 bar) at high catalyst concentration than at low one (from 15 to $20 \%$ ).

More in general, organics conversion and hydrogen productivity are not always correlated with each other, depending on the conversion pathway and intermediates conversion or accumulation. In turn, the latter depend on the operating conditions and on the byproducts appearing in the gas phase. For instance, glucose adsorbs over the catalyst surface, donates progressively electrons to saturate the forming holes, thus closing the circuit during electrons promotion in the conduction band. Each two electrons used for the production of one $\mathrm{H}_{2}$ molecule lead to more and more oxidised organic species, until the elimination of $\mathrm{CO}_{2}$ molecules occur. Based on the operating conditions and catalyst properties (e.g. the adsorption/desorption thermodynamics and kinetics for the substrate and each intermediate, compared with hydrogen production kinetics) the intermediate itself may remain adsorbed over the surface or released in the aqueous environment, so jeopardising the correlation between hydrogen formation rate and carbon conversion. 
Therefore, it is advisable to consider separately the two outcomes, of course making prevail the hydrogen yield in the decision point.

\section{Effect or reaction temperature}

The effect of reaction temperature is reported in Table 2 (Tests 2, 6-8), which evidences negligible conversion and hydrogen productivity at the lowest temperature $\left(20^{\circ} \mathrm{C}\right)$. A slight increase of temperature showed a negligible effect on hydrogen productivity, which increased significantly only at the highest temperature. At $80^{\circ} \mathrm{C}$ the conversion was lower than at $60^{\circ} \mathrm{C}$, but yet appreciable (ca. $35 \%$ after $5 \mathrm{~h}$, test 2 ). However, the main effect is the improvement of $\mathrm{H}_{2}$ productivity. Indeed, by increasing by $40^{\circ} \mathrm{C}$ the temperature, an increase by one order of magnitude of $\mathrm{H}_{2}$ productivity was achieved.

We suppose that increasing temperature can favour all the consecutive steps that lead to glucose progressive decomposition with full reforming. A different glucose conversion path is instead active at low temperature, e.g. its oxidative conversion, which is ineffective for the production of $\mathrm{H}_{2}$.

This parameter has been scarcely investigated in the literature, with results on the hydrogen productivity very similar to those here reported, but unknown effect on glucose conversion. The higher efficiency at higher temperature has been explained on the basis of faster auxiliary steps $[25,28]$, but it is not trivial, since higher thermal motion and disorder could also favour dissipative charge recombination.

The increase of temperature should be also considered as for convenience on the overall thermal management of the system. In the present case the temperature is set and controlled through a thermosetting system, but that temperature can be reached (on a $1 \mathrm{~L}$ scale, with the presently used irradiance), through the lamp heating effect, by eliminating the cooling circuit. Thus, provided that on a scaled up plant the calculation should be 
rigorously take into account the geometry, volume and irradiance through the solution, it can be envisaged that external heating may not be needed to keep such temperature level.

\section{Effect of catalyst concentration}

The effect of catalyst concentration is reported in Table 2 (Tests 2, 5, 10-12). When examining the productivity of hydrogen, an exponential increase is observed when decreasing the catalyst loading in the reactor over more than one order of magnitude. However, by looking at the absolute $\mathrm{H}_{2}$ amount produced (Figure 5), i.e. not normalised over catalyst amount, much lower difference is observed. Nevertheless, low catalyst concentrations led to higher hydrogen productivity, with the best result achieved at $0.25 \mathrm{~g} / \mathrm{L}$. Meanwhile, organics conversion decreased from $35 \%$ at $1 \mathrm{~g} / \mathrm{L}$ catalyst concentration to $21 \%$ at $0.0625 \mathrm{~g} / \mathrm{L}$. So, an intermediate catalyst concentration $(0.25 \mathrm{~g} / \mathrm{L})$ represents a reasonable compromise between the higher hydrogen yield and organics conversion.

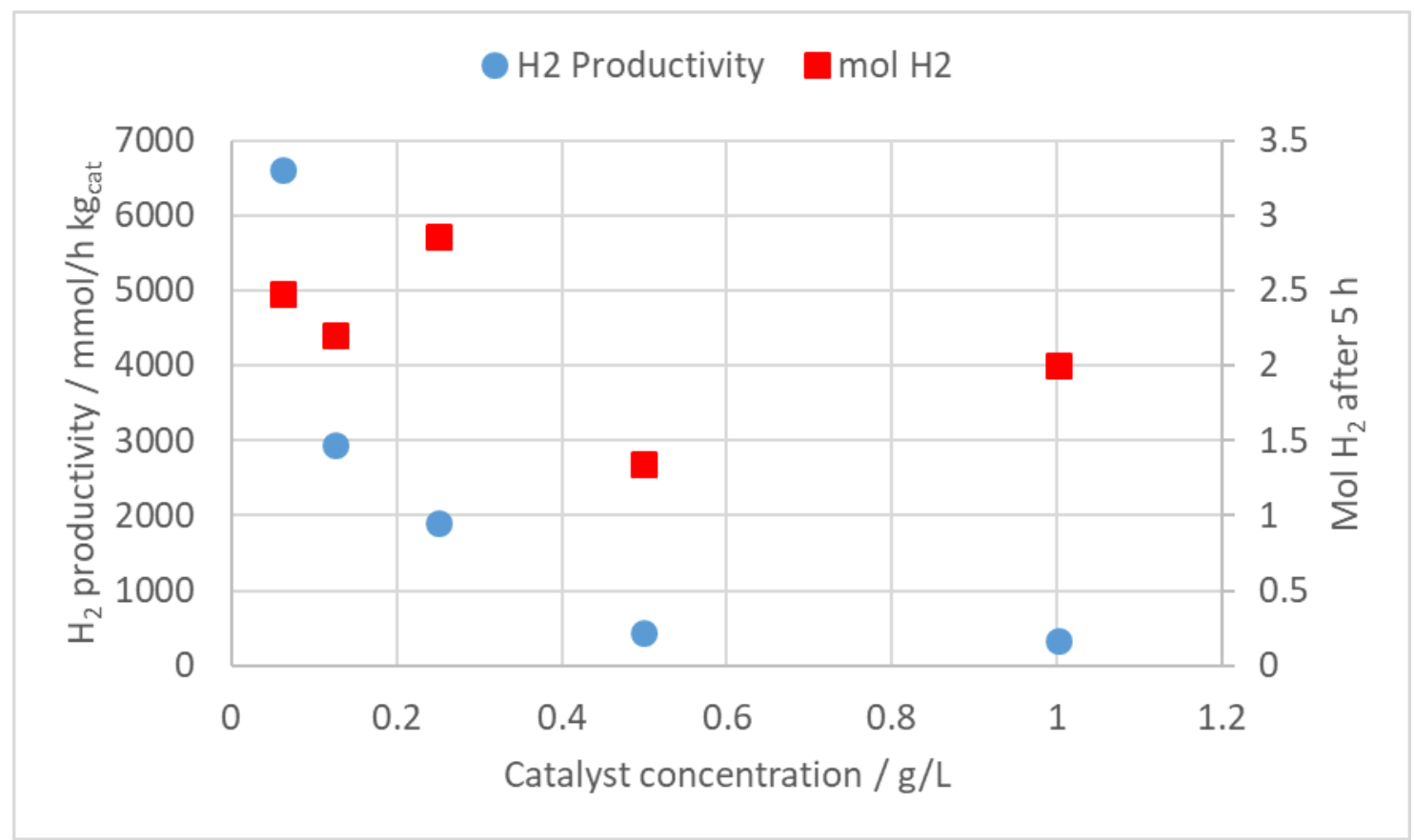


Figure 5: Effect of catalyst concentration on $\mathrm{H}_{2}$ productivity and on the total moles of $\mathrm{H}_{2}$ produced after $5 \mathrm{~h}$ testing. $\mathrm{P}=4$ bar, $\mathrm{T}=80^{\circ} \mathrm{C}$, glucose concentration $=5 \mathrm{~g} / \mathrm{L}, \mathrm{pH}=5.5$. Measured irradiance (average in the reactor) $=256 \mathrm{~W} / \mathrm{m}^{2}$.

The effect of catalyst concentration is much more studied and responds to opposite requisites. On one hand, high concentration of the solid shields and scatters the incoming light, preventing a uniform irradiation of all the suspension, with very poor light penetration. On the other hand, too low catalyst amount depresses the possibility to convert the substrate due to an obvious lack of active sites. A compromise should be searched from this point of view, which has been found in the intermediate $0.25 \mathrm{~g} / \mathrm{L}$ concentration with our experimental set up. The same optimal concentration has been recently reported for $\mathrm{Pt} / \mathrm{rGO} / \mathrm{TiO}_{2}$ catalysts in the case of glycerol photoreforming [48]. It should be stressed that this parameter cannot be regarded as universal, as it may happen in conventional fixed bed catalytic reactors, where the definition of a space velocity or a contact time uniquely defines a performance state. Indeed, in this slurry system the efficiency of mixing and the irradiance concur in determining the optimal amount of catalyst, which may vary depending on the selected photoreactor geometry, configuration and mixing.

\section{Effect of substrate concentration and type}

The effect of glucose concentration is reported in Table 2 (Tests 5 and 9). Both the conversion and the hydrogen productivity decreased when increasing the glucose concentration. This has been attributed to surface saturation at the highest glucose concentration, which limits the consecutive reaction steps that can lead to the full carbon removal and to improve hydrogen production. The same behaviour, thug in a different concentration range, has been also reported for the photoreforming of glycerol (maximum $\mathrm{H}_{2}$ productivity at 20 vol\% substrate concentration) [48]. It should be also mentioned that 
increasing glucose concentration also showed detrimental in a completely different route to $\mathrm{H}_{2}$, such as the use of hydrogenase with E. coli $[49,50]$.

$5 \mathrm{~g} / \mathrm{L}$ has been considered as a compromise between the need to achieve full conversion of the organic species and high hydrogen productivity, and the convenience to increase the substrate concentration. Indeed, biomass conversion is conveniently carried out leading to concentrated hydrolysed solutions, provided that they can remain sufficiently stable, without precipitation of humines. Indeed, depending of the hydrolysis conditions (and of biomass type), a different spectrum of products can be expected. Under milder hydrolysis conditions glucose yield can be maximised (e.g. 15-30\%), but with a significant concentration of condensable by-products, that may decrease the overall yield of the process and deposit over the plant lines and on the subsequent photoreforming catalyst and apparatus. Also, this often results in a viscous solution with significant issues for suspension of the catalyst and transparency. These issues may be solved by using more diluted solutions (for instance most literature on photoreforming deals with glucose concentration $<1 \mathrm{~g} / \mathrm{L})$. Nevertheless, such a low concentration severely limits the productivity and volumetric efficiency of the process. Thus, a concentration of $5 \mathrm{~g} / \mathrm{L}$ resulted a reasonable compromise between the two points. The need of low substrate concentration in general opens the way to the use of sugar containing waste waters that are typically diluted.

A totally different approach can rely on the execution of the biomass hydrolysis step under harsh conditions. This typically leads to a much cleaner and stable solution, which consists of levulinic + formic acids (1:1 molar ratio), where the possible by-products and residues are solids easily separable from the liquid products. On this ground, we also explored the possibility to photoreform this latter products mixture (Figure 6). To the best of our knowledge, it is the first time that levulinic acid is used as substrate for this reaction, pure or mixed with formic acid. 


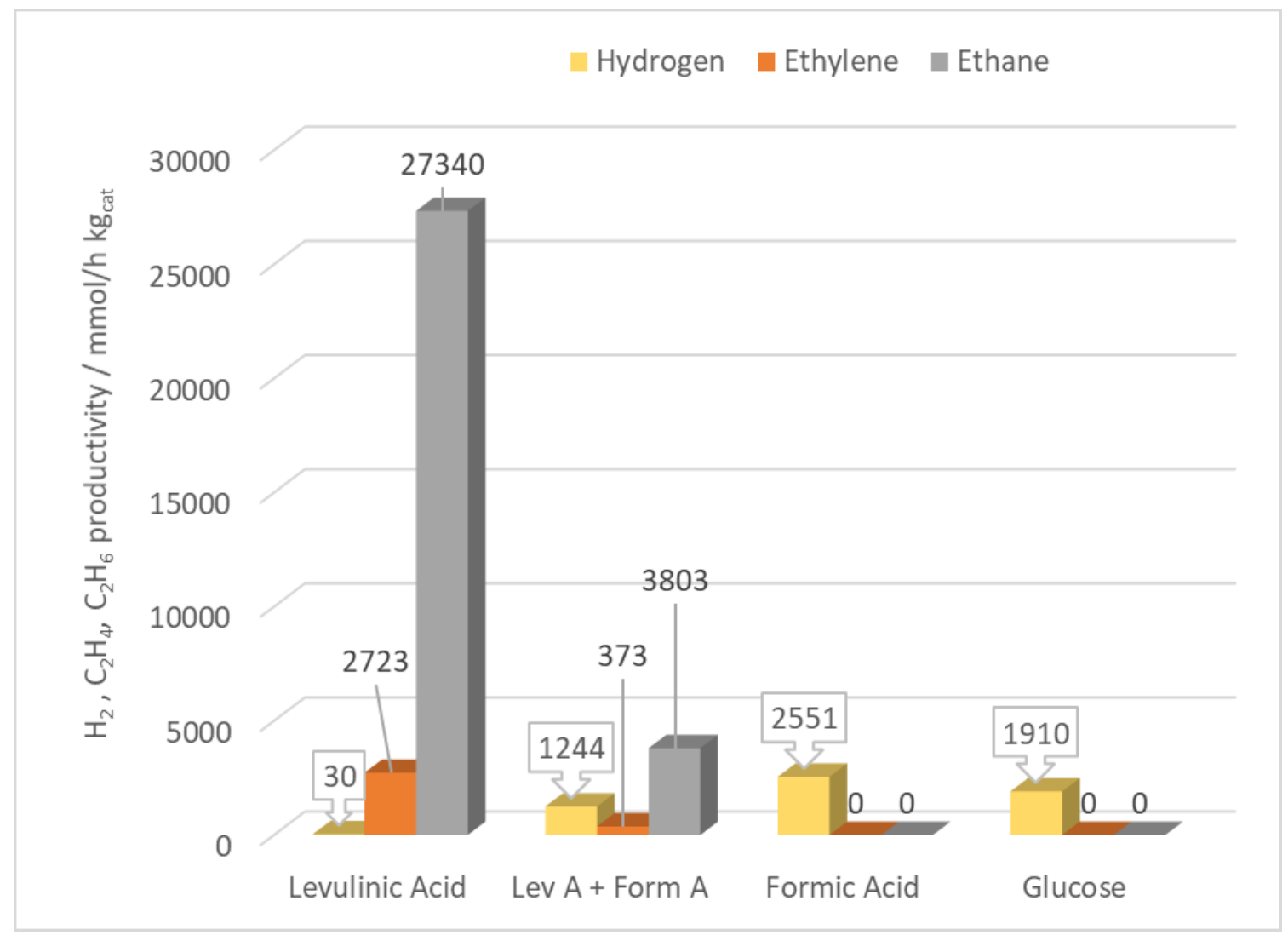

Figure 6: Effect of substrate type on hydrogen, ethylene and ethane productivity. $\mathrm{P}=4$ bar, $\mathrm{T}=80^{\circ} \mathrm{C}$, catalyst concentration $=0.25 \mathrm{~g} / \mathrm{L}$, substrate concentration $=5 \mathrm{~g} / \mathrm{L}$. The $\mathrm{pH}$ was left as native after the preparation of the solution: 5.5 for glucose, levulinic acid 4 , formic acid 2.5, levulinic + formic acid 3. Measured irradiance (average in the reactor) $=256 \mathrm{~W} / \mathrm{m}^{2}$. Catalyst P25.

Levulinc acid led to very low hydrogen productivity, whereas formic acid was the most productive one, leading to $2.5 \mathrm{~mol} \mathrm{H} / \mathrm{h} \mathrm{kg}_{\text {cat }}$. Their $1: 1$ mixture produced an average value between the two, letting surmise that only formic acid is substantially converted. The organics conversion was ca. $19 \%$ in the case of pure formic acid, comparable with the $20 \%$ conversion achieved with glucose, while it was much lower in the case of pure levulinic acid, ca. $6 \%$.

In order to understand the reactivity of levulinic acid we deepened the products distribution (Figure 6). If the fragmentation of glucose and formic acid led to the production of $\mathrm{H}_{2}, \mathrm{CO}$ 
and $\mathrm{CO}_{2}$ as the only products in the gas phase, with levulinic acid, besides a minor fraction of $\mathrm{H}_{2}$ we have observed the formation of a significant amount of ethylene and most of all ethane.

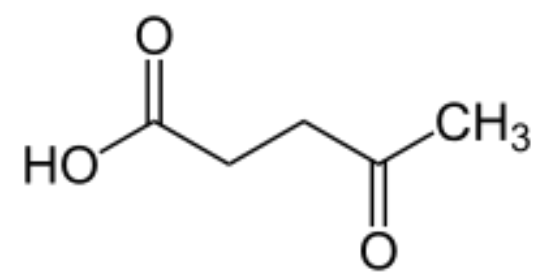

According to the molecular structure of levulinic acid, we can hypothesise as a first step to achieve the decarboxylation of the carboxylic group according to conventional fragmentation through the elimination of a $\mathrm{C} 1$ fragment, subsequently reformed. The same fate can be achieved on the opposite carbonyl group. However, the central $\mathrm{CH}_{2}-\mathrm{CH}_{2}$ fragment, either saturated or unsaturated, can be sufficiently stable and less interacting with catalyst surface to be desorbed. Indeed, higher concentration in gas phase was observed for ethane, much less polarisable than the unsaturated moiety (ethylene), which may remain more favourably adsorbed on the catalyst for further conversion or side reactions.

\section{Effect of reactor size and irradiance}

Finally, we have compared two different photoreactors with different size.

The first semi-pilot scale system was compared with a more compact photoreactor, with similar geometric asset (similar length to diameter, immersion axial lamp), but with 0.25 suspension volume instead of $1.2 \mathrm{~L}$. The lamp power was also different, $125 \mathrm{~W}$ for the biggest reactor with respect to $75 \mathrm{~W}$ for the smallest one, to avoid overheating of the solution. Accordingly, the average irradiance was lower for the smaller reactor, i.e. $45 \mathrm{~W} / \mathrm{m}^{2}$, to be compared with $265 \mathrm{~W} / \mathrm{m}^{2}$ for the biggest one. The productivity of $\mathrm{H}_{2}$ was determined under the optimised reaction conditions as for catalyst and glucose concentration. However, the smallest reactor was made in glass and thus it allowed only ambient pressure operation. Accordingly, we also decreased the operating temperature to $60^{\circ} \mathrm{C}$ in order to avoid 
excessive evaporation of the solution during the test, not significant at higher pressure, which would have significantly varied the substrate and catalyst concentration at increasing reaction time.

$1642 \mathrm{mmol} / \mathrm{h} \mathrm{kg}_{\text {cat }}$ of $\mathrm{H}_{2}$ have been determined in the smaller reactor at $60^{\circ} \mathrm{C}$, with a $17 \%$ conversion of the organic material. Also in this case, the operation at room temperature led to negligible hydrogen productivity both at $0.25 \mathrm{~g} / \mathrm{L}$ of catalyst or $1 \mathrm{~g} / \mathrm{L}$. Overall, the operation at pressure above the ambient one, on one hand disfavoured gas evolution reactions, but proved very interesting at moderate levels (2-4 bar) to allow an increase of temperature with boosting $\mathrm{H}_{2}$ productivity.

The comparison between the two reactors allowed to prove that a scaled up reactor is feasible and allows increased hydrogen productivity. Indeed, the best hydrogen productivity here achieved was between 2.0 and $6.6 \mathrm{~mol} / \mathrm{h} \mathrm{kg}_{\mathrm{cat}}$, which is one of the best achievements among those reviewed in Table 3. It should be also underlined that this explorative investigation has been carried out with a very simple catalyst, a commercial material, inexpensive and durable. Further improvement of this performance is expected through optimisation of the catalyst formulation, which is also welcome to achieve more efficient solar light harvesting. According to various literature reports, it can be expected to further boost by 1-2 orders of magnitude the hydrogen productivity.

A final comparison of these results with the most recent and promising literature results is reported in Table 3. Of course comparisons can only be indicative since the results strictly depend not only on catalyst formulation, but also on photoreactor assembly and irradiance.

\begin{tabular}{|c|c|c|c|c|}
\hline Catalyst & $\begin{array}{c}\text { Hole } \\
\text { Scavenger }\end{array}$ & $\begin{array}{c}\text { Lamp } \\
\text { power/irradiance }\end{array}$ & $\begin{array}{c}\mathbf{H}_{\mathbf{2}} \mathbf{\text { prod}} . \\
\left(\mathbf{m o l} / \mathbf{k g}_{\text {cat }} \mathbf{h}\right)\end{array}$ & Reference \\
\hline $\mathrm{TiO}_{2} \mathrm{P} 25$ & Glucose & $256 \mathrm{~W} / \mathrm{m}^{2}$ & $2.0-6.6$ & This work \\
\hline $\mathrm{TiO}_{2} \mathrm{P} 25$ & Formic acid & $256 \mathrm{~W} / \mathrm{m}^{2}$ & 2.6 & This work \\
\hline
\end{tabular}




\begin{tabular}{|c|c|c|c|c|}
\hline $\mathrm{TiO}_{2} \mathrm{P} 25$ & Levulinic acid & $256 \mathrm{~W} / \mathrm{m}^{2}$ & $\begin{array}{c}0.03 \mathrm{H}_{2}+2.7 \\
\mathrm{C}_{2} \mathrm{H}_{4}+27.3 \\
\mathrm{C}_{2} \mathrm{H}_{6}\end{array}$ & This work \\
\hline $\mathrm{Pt} / \mathrm{TiO}_{2}$ & $\begin{array}{l}\text { Glucose from } \\
\text { pure cellulose } \\
\text { hydrolysis }\end{array}$ & $250 \mathrm{~W}$ & 0.492 & [35] \\
\hline Graphite $/ \mathrm{TiO}_{2} / \mathrm{NiO}_{x}$ & $\begin{array}{l}\text { Glucose and } \\
\text { glucose form } \\
\text { cellulose } \\
\text { hydrolysis }\end{array}$ & $500 \mathrm{~W}$ & 4.1 & [28] \\
\hline $8.9 \mathrm{wt} \% \mathrm{Au} / \mathrm{TiO}_{2}$ & Methanol & $\begin{array}{c}200 \mathrm{~W}, 20 \\
\mathrm{~mW} / \mathrm{cm}^{2}\end{array}$ & 2.8 & [51] \\
\hline $0.5 \mathrm{wt} \% \mathrm{Pt} / \mathrm{TiO}_{2}$ & Glucose & $125 \mathrm{~W}$ & 1 & [26] \\
\hline $\mathrm{Pt} / \mathrm{TiO}_{2}$ & Swine sewage & 60 W UVA & 0.075 & [32] \\
\hline $\mathrm{Rh} / \mathrm{TiO}_{2}$ & Glucose & $300 \mathrm{~W}$ & 0.56 & [33] \\
\hline $\mathrm{Pd} / \mathrm{TiO}_{2}$ & Glucose & $5 \mathrm{~mW} / \mathrm{cm}^{2}$ & 8 & [25] \\
\hline $\mathrm{CdS} / \mathrm{MoS}_{2}$ & Glucose & $\begin{array}{c}300 \text { W, visible } \\
\text { light }\end{array}$ & $\begin{array}{c}45.5 \\
\text { (Decreasing } \\
\text { activity from } \\
\text { run to run) }\end{array}$ & [24] \\
\hline $\mathrm{TiO}_{2}$ & Glucose & $\begin{array}{c}112 / 300 / 1000 \mathrm{~W} \\
\text { visible }\end{array}$ & $\begin{array}{l}\text { - (oxidation } \\
\text { glucose) }\end{array}$ & [23] \\
\hline $\mathrm{Pt} / \mathrm{TiO}_{2}$ & $\begin{array}{l}\text { Hydrolised } \\
\text { solution from } \\
\text { pinewood }\end{array}$ & $200 \mathrm{~mW} / \mathrm{cm}^{2}$ & $\begin{array}{c}0.000833 \text { (not } \\
\text { normalised } \\
\text { per cat mass) } \\
\text { Productivity } \\
\text { steadily } \\
\text { decreasing in } \\
\text { consecutive } \\
\text { runs } \\
\end{array}$ & [34] \\
\hline $\mathrm{LaFeO}_{3}$ & Glucose & $10 \mathrm{~W}$ & 0.395 & [22] \\
\hline $\mathrm{TiO}_{2}$ & Glucose & $10 \mathrm{~W}$ & 2.5 & [21] \\
\hline $\mathrm{Ru} / \mathrm{LaFeO}{ }_{3}-\mathrm{Fe}_{2} \mathrm{O}_{3}$ & Glucose & - (Vis light) & 0.91 & {$[15,20]$} \\
\hline $\mathrm{Pt} / \mathrm{g}-\mathrm{C}_{3} \mathrm{~N}_{4}$ & Glucose & $\begin{array}{c}797 \mathrm{~W} / \mathrm{m}^{2} \\
\text { (natural solar } \\
\text { light) }\end{array}$ & 1.37 & [19] \\
\hline $\mathrm{Fe}_{2} \mathrm{O}_{3}$ & Glucose & $\begin{array}{l}150 \text { W Simulated } \\
\text { sunlight }\end{array}$ & $\begin{array}{c}10(\mathrm{mmol} / \mathrm{h} \\
\left.\mathrm{m}^{2}\right)\end{array}$ & [52] \\
\hline $\mathrm{Pt} / \mathrm{TiO}_{2}$ & Cellulose & $\begin{array}{l}\text { UVA ( } 60 \mathrm{~W}) \text { or } \\
\text { simulated solar } \\
\text { light or natural } \\
\text { solar light }\end{array}$ & 0.067 & [32] \\
\hline $\mathrm{NiO} / \mathrm{TiO}_{2}$ & Methanol & UVA $1.6 \mathrm{~W}$ & 2.7 & [53] \\
\hline
\end{tabular}




\begin{tabular}{|c|c|c|c|c|}
$\mathrm{Cu}_{2} \mathrm{O} / \mathrm{TiO}_{2}$ & Glycerol & $400 \mathrm{~W}$ & 0.67 & {$[54]$} \\
\hline $\mathrm{TiO}_{2} / \mathrm{rGO} / \mathrm{Pt}$ & Glycerol & $450 \mathrm{~W}$ & 70 & {$[47]$} \\
\hline $\mathrm{Ag}_{2} \mathrm{O} / \mathrm{TiO}_{2}$ & Glycerol & $300 \mathrm{~W} \mathrm{Xe}$ arc & 0.30 & {$[55]$} \\
\hline $\mathrm{Pt} / \mathrm{TiO}_{2}$ & Cellulose & $150 \mathrm{~W}$ & 0.15 & {$[27]$} \\
\hline
\end{tabular}

Table 3: Comparison of literature data.

\section{Addition of metal co-catalysts}

In order to improve further the productivity we have added different noble metal co-catalysts to titania (Table 2, tests 13-16). All the selected metals showed a beneficial effect on hydrogen productivity, with a productivity order $\mathrm{Pt}>\mathrm{Au}>\mathrm{Pd}>\mathrm{Ag}$. The highest hydrogen productivity, reaching ca. $15 \mathrm{~mol} / \mathrm{h} \mathrm{kg}_{\text {cat }}$ and glucose conversion (26\% after $5 \mathrm{~h}$ ) was obtained by adding $0.1 \mathrm{~mol} \% \mathrm{Pt}$ as co-catalyst. Furthermore, by looking to the products distribution in gas phase one may observe that the presence of the metal induces the formation of additional products in gas phase, such as ethane and ethylene (Figure 7). As in the case of levulinic acid this can be interpreted through the formation of sufficiently stable $\mathrm{C} 2$ fragments on the surface of the catalyst that desorb and move to the gas phase. This is detrimental if the goal of the process is the production of pure $\mathrm{H}_{2}$, but may be favourable if one desires the production of a gaseous fuel mixture, because these C2 compounds increase the heating power of the gas. 


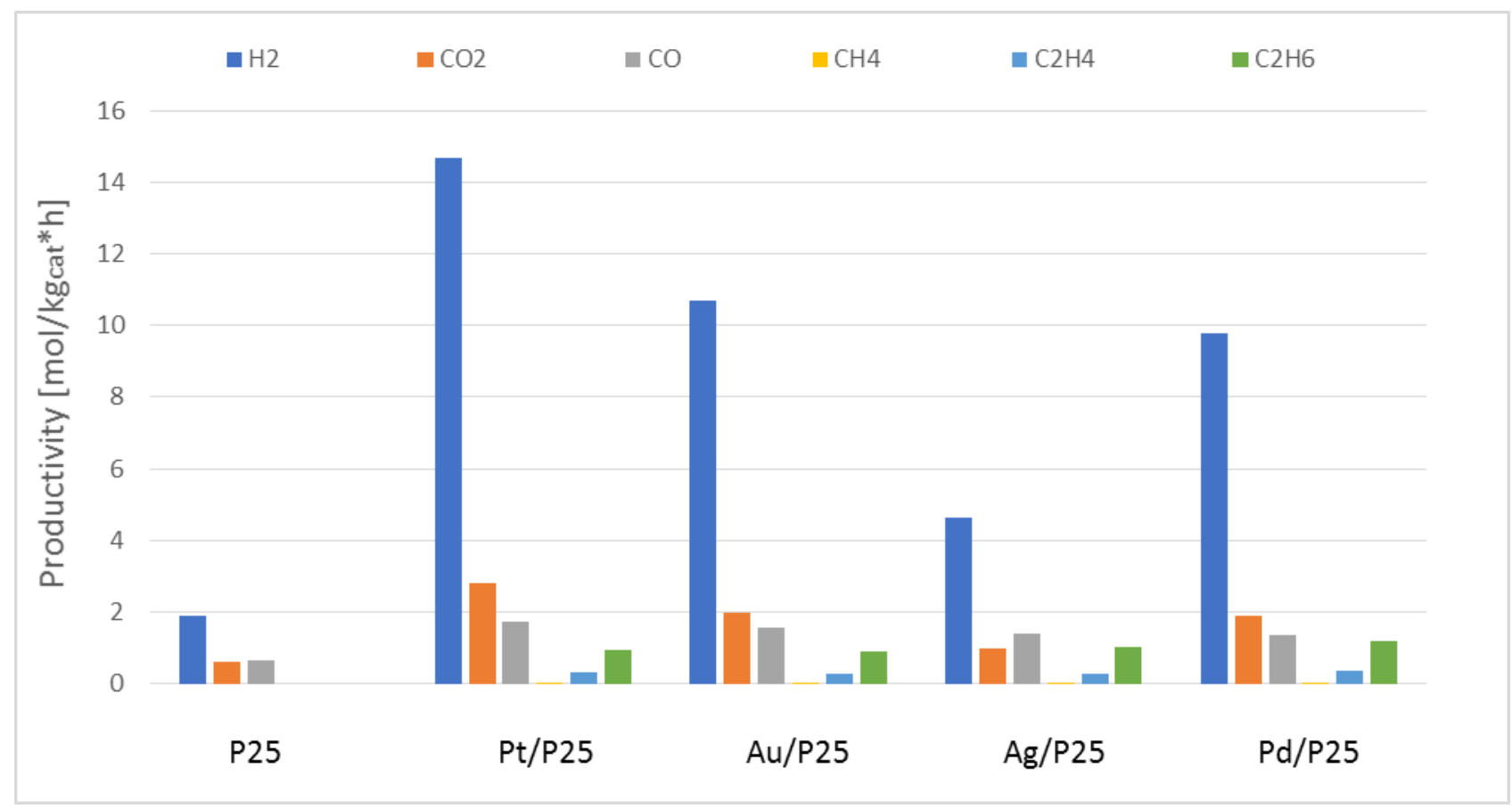

Figure 7: Energy band positions, including the conduction and valence bands of the semiconductor, the work functions of the noble metals, and the electrochemical potentials of the redox couples involved.

The enhancement of photocatalytic activity, especially with $\mathrm{Pt}$, is in agreement with literature $[2,4,56]$. The hydrogen evolution is favoured for metals presenting a low hydrogen overpotential: the lowest overpotential for $\mathrm{H}_{2}$ is the one with $\mathrm{Pt}$ [57]. The other reason for the success of Pt can be explained according to its workfunction: the higher the latter, the greater the Schottky barrier formed between the metal and the semiconductor, the lower the recombination time for the photogenerated electron/hole pair and the higher the photoactivity. The metals workfunctions must be higher than that of $\mathrm{TiO}_{2}$, which is $4.0 \mathrm{eV}$ [58], which is true for all the metals employed, namely Pt (6.35 eV), Pd (5.12 eV), Au (5.10 $\mathrm{eV})$ and $\mathrm{Ag}(4.64 \mathrm{eV})$ [59]. A visual scheme is provided in Figure 8.

After Pt, the best performance was achieved with $\mathrm{A}$, which, however, is expected to behave as Pd according to the workfunction values. The higher activity can be ascribed to its wellknown surface plasmon resonance feature [60-63]. The localized surface plasmon 
resonance (LSPR) is responsible, after light absorption, to enhance the absorption, the local electric field and excitation of active electrons and holes [63]. LSPR polarizes the reactant molecules in the fluid and increases the adsorption to the metal surface, also heating up the local environment, so that the mass transfer of the molecules is greater and, consequently, also the reaction rates.

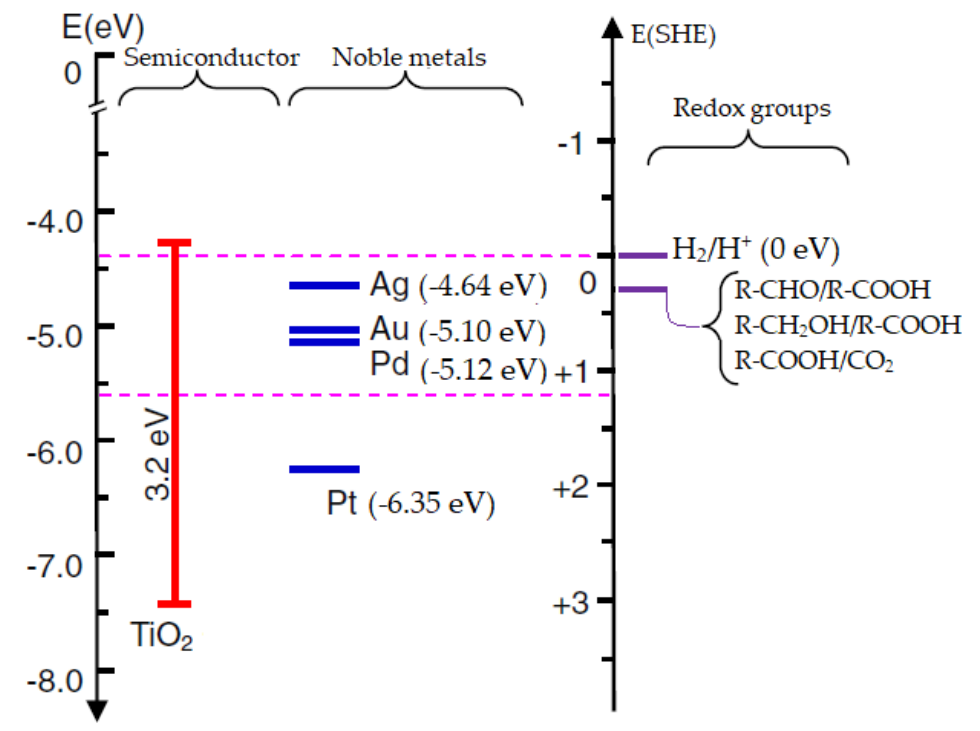

Figure 8: Energy band positions, including the conduction and valence bands of the semiconductor, the work functions of the noble metals, and the electrochemical potentials of the redox couples involved.

\section{4 - Conclusions}

The operating conditions for glucose photoreforming have been investigated in two geometrically similar photoreactors from the lab to a semi-pilot scale. Glucose photoreforming was effective to achieve significant hydrogen productivity at high temperature $\left(60-80^{\circ} \mathrm{C}\right)$, also thanks to moderate pressure above the ambient value (2-4 bar). Increasing glucose concentration disfavoured the reaction, as well as high catalyst loading. 
Hydrogen productivity as high as $6.6 \mathrm{~mol} \mathrm{H}_{2} / \mathrm{h} \mathrm{kg}$ cat has been achieved with a very simple commercial photocatalyst as P25.

Different parameters were investigated such as temperature, which proved one of the most sensitive, pressure (possible only thanks to a specifically designed high pressure photoreactor prototype, glucose and catalyst concentration.

Under optimised reaction conditions, the addition of a metal co-catalyst proved in every case effective to improve the productivity of $\mathrm{H}_{2}$. The highest productivity was achieved with 0.1 mol\% $\mathrm{Pt}$ due to its higher workfunction in absolute value, which make it an effective electron trap. Furthermore, it has the lowest overpotential for $\mathrm{H}_{2}$ among this group.

The photoconversion of levulinic acid and of its 1:1 mixture with formic acid has also been investigated as an attempt to exploit the products of biomass hydrolysis under harsh conditions. While formic acid was very active for $\mathrm{H}_{2}$ production, levulinic acid was negligible from this point of view, mainly leading to ethane and ethylene as gas phase products.

\section{Acknowledgements}

I. Rossetti and E. Bahadori are grateful to Fondazione Cariplo and Regione Lombardia for financial support through the grant 2016-0858 - Up-Unconventional Photoreactors.

The financial contribution of MIUR through the PRIN2015 grant (20153T4REF) is gratefully acknowledged (G. Ramis and I. Rossetti).

The authors are grateful to the MoS graduating students Andrea Villa and Federico Sellerio for their experimental efforts.

\section{References}

[1] Beltram A, Romero-Ocaña I, Josè Delgado Jaen J, Montini T, Fornasiero P. Photocatalytic valorization of ethanol and glycerol over TiO2 polymorphs for 
sustainable hydrogen production. Appl Catal A Gen 2016;518:167-75. doi:10.1016/j.apcata.2015.09.022.

[2] Christoforidis KC, Fornasiero P. Photocatalytic hydrogen production: a rift into the future energy supply. ChemCatChem 2017;9:1523-44. doi:10.1002/cctc.201601659.

[3] Montini T, Monai M, Beltram A, Romero-ocaña I, Fornasiero P. H2 production by photocatalytic reforming of oxygenated compounds using TiO2 -based materials. Mater Sci Semicond Process 2016;42:122-30. doi:10.1016/j.mssp.2015.06.069.

[4] Rossetti I. Hydrogen production by photoreforming of renewable substrates. ISRN Chem Eng 2012;2012:1-21. doi:10.5402/2012/964936.

[5] Dosado AG, Chen W-T, Chan A, Sun-Waterhouse D, Waterhouse GIN. Novel $\mathrm{Au} / \mathrm{TiO} 2$ photocatalysts for hydrogen production in alcohol-water mixtures based on hydrogen titanate nanotube precursors. J Catal 2015;330:238-254.

[6] Selli E, Chiarello GL, Quartarone E, Mustarelli P, Rossetti I, Forni L. A photocatalytic water splitting device for separate hydrogen and oxygen evolution. Chem Commun 2007:5022-4. doi:10.1039/b711747g.

[7] Rossetti I, Bahadori E, Tripodi A, Villa A, Prati L, Ramis G. Conceptual design and feasibility assessment of photoreactors for solar energy storage. Sol Energy 2018;172:225-31. doi:https://doi.org/10.1016/j.solener.2018.02.056.

[8] Serra M, Baldovi HG, Albarracin F, Garcia H. Visible light photocatalytic activity for hydrogen production from water-methanol mixtures of open-framework $V$-doped mixed-valence titanium phosphate. Appl Catal B Environ 2016;183:159-67. doi:10.1016/j.apcatb.2015.10.027.

[9] Alenzi N, Liao W, Cremer PS, Sanchez-torres V, Wood TK, Ehlig-economides C, et al. Photoelectrochemical hydrogen production from water / methanol decomposition using Ag / TiO2 nanocomposite thin films. Int J Hydrogen Energy 2010;35:1176875. doi:10.1016/j.ijhydene.2010.08.020. 
[10] Beltram A, Melchionna M, Montini T, Nasi L, Fornasiero P, Prato M. Making $\mathrm{H}_{2}$ from light and biomass-derived alcohols: the outstanding activity of newly designed hierarchical MWCNT/Pd@TiO 2 hybrid catalysts. Green Chem 2017:2379-89. doi:10.1039/C6GC01979J.

[11] Sanwald KE, Berto TF, Jentys A, Camaioni DM, Gutie OY, Lercher JA. Kinetic coupling of water splitting and photoreforming on $\mathrm{SrTiO}^{-}$- based photocatalysts. ACS Catal 2018;8:2902-13. doi:10.1021/acscatal.7b03192.

[12] Sola AC, Homs N, Ramírez de la Piscina P. Photocatalytic H2 production from ethanol(aq) solutions: The effect of intermediate products. Int J Hydrogen Energy 2016;41:19629-36. doi:10.1016/j.jjhydene.2016.05.268.

[13] Velázquez JJ, Fernández-González R, Díaz L, Pulido Melián E, Rodríguez VD, Núñez P. Effect of reaction temperature and sacrificial agent on the photocatalytic H2-production of Pt-TiO2. J Alloys Compd 2017;721:405-10.

doi:10.1016/j.jallcom.2017.05.314.

[14] López-Tenllado FJ, Hidalgo-Carrillo J, Montes V, Marinas A, Urbano FJ, Marinas JM, et al. A comparative study of hydrogen photocatalytic production from glycerol and propan-2-ol on M/TiO2 systems (M=Au, Pt, Pd). Catal Today 2017;280:58-64. doi:10.1016/j.cattod.2016.05.009.

[15] lervolino G, Vaiano V, Sannino D, Rizzo L, Palma V. Enhanced photocatalytic hydrogen production from glucose aqueous matrices on Ru-doped $\mathrm{LaFeO}$. Appl Catal B Environ 2017;207:182-94. doi:10.1016/j.apcatb.2017.02.008.

[16] Vaiano V, lervolino G, Sarno G, Sannino D, Rizzo L, Murcia Mesa JJ, et al. Simultaneous production of $\mathrm{CH} 4$ and $\mathrm{H} 2$ from photocatalytic reforming of glucose aqueous solution on sulfated Pd-TiO 2 catalysts. Oil Gas Sci Technol - Rev d'IFP Energies Nouv 2015;70:891-902. doi:10.2516/ogst/2014062.

[17] Sanwald KE, Berto TF, Eisenreich W, Jentys A, Gutiérrez OY, Lercher JA. 
Overcoming the rate-limiting reaction during photoreforming of sugar aldoses for $\mathrm{H} 2$ generation. ACS Catal 2017;7:3236-44. doi:10.1021/acscatal.7b00508.

[18] Ibrahim N, Kamarudin SK, Minggu LJ. Biofuel from biomass via photoelectrochemical reactions: An overview. J Power Sources 2014;259:33-42. doi:10.1016/j.jpowsour.2014.02.017.

[19] Speltini A, Scalabrini A, Maraschi F, Sturini M, Pisanu A, Malavasi L, et al. Improved photocatalytic $\mathrm{H} 2$ production assisted by aqueous glucose biomass by oxidized gC3N4. Int J Hydrogen Energy 2018;43:14925-33.

doi:10.1016/j.ijhydene.2018.06.103.

[20] lervolino G, Vaiano V, Sannino D, Rizzo L, Galluzzi A. Hydrogen production from glucose degradation in water and wastewater treated by $\mathrm{Ru}-\mathrm{LaFeO} 3$ / Fe2O3 magnetic particles photocatalysis and heterogeneous photo-Fenton. Int $\mathrm{J}$ Hydrogen Energy 2017;43:2184-96. doi:10.1016/j.ijhydene.2017.12.071.

[21] Iervolino G, Vaiano V, Murcia JJ, Rizzo L, Ventre G, Pepe G, et al. Photocatalytic hydrogen production from degradation of glucose over fluorinated and platinized TiO2 catalysts. J Catal 2016;339:47-56. doi:10.1016/j.jcat.2016.03.032.

[22] lervolino G, Vaiano V, Sannino D, Rizzo L, Ciambelli P. Production of hydrogen from glucose by $\mathrm{LaFeO} 3$ based photocatalytic process during water treatment. Int $\mathrm{J}$ Hydrogen Energy 2015;41:959-66. doi:10.1016/j.jijhydene.2015.10.085.

[23] Vià L Da, Recchi C, Gonzalez-ya EO, Davies TE, Lopez-sanchez JA. Visible light selective photocatalytic conversion of glucose by TiO 2. Appl Catal B Environ 2017;202:281-8. doi:10.1016/j.apcatb.2016.08.035.

[24] Li C, Wang H, Ming J, Liu M, Fang P. Hydrogen generation by photocatalytic reforming of glucose with heterostructured CdS / MoS2 composites under visible light irradiation. Int J Hydrogen Energy 2017;42:16968-78. doi:10.1016/j.ijhydene.2017.05.137. 
[25] Gomathisankar P, Yamamoto D, Katsumata H, Suzuki T, Kaneco S. Photocatalytic hydrogen production with aid of simultaneous metal deposition using titanium dioxide from aqueous glucose solution. Int J Hydrogen Energy 2013;38:5517-24. doi:10.1016/j.ijhydene.2013.03.014.

[26] Bellardita M, Garcìa-Lòpez El, Marcì G, Palmisano L. Photocatalytic formation of H2 and value-added chemicals in aqueous glucose ( $\mathrm{Pt}$ ) - TiO2 suspension. Int $\mathrm{J}$ Hydrog Energy 2016;41:5934-47. doi:10.1016/j.jjhydene.2016.02.103.

[27] Caravaca A, Jones W, Hardacre C, Bowker M. H2 production by the photocatalytic reforming of cellulose and raw biomass using $\mathrm{Ni}, \mathrm{Pd}, \mathrm{Pt}$ and $\mathrm{Au}$ on titania. Proc $\mathrm{R}$ Soc A 2016;472:20160054. doi:dx.doi.org/10.1098/rspa.2016.0054.

[28] Zhang L, Wang W, Zeng S, Yang S, Hao H. Enhanced H2 evolution from photocatalytic cellulose conversion based on graphitic carbon layers on $\mathrm{TiO} / \mathrm{NiOx}$. Green Chem 2018;20:3008-13. doi:10.1039/c8gc01398e.

[29] Speltini A, Sturini M, Dondi D, Annovazzi E, Maraschi F, Caratto V, et al. Sunlight promoted photocatalytic hydrogen gas evolution from water-suspended cellulose : a systematic study. Photochem Photobiol Sci 2014;13:1410-9. doi:10.1039/c4pp00128a.

[30] Kuehnel MF, Reisner E. Solar hydrogen generation from lignocellulose. Angew Chemie - Int Ed 2018;57:3290-6. doi:10.1002/anie.201710133.

[31] Balducci G. The adsorption of glucose at the surface of anatase : A computational study. Chem Phys Lett 2010;494:54-9. doi:10.1016/j.cplett.2010.05.068.

[32] Speltini A, Sturini M, Maraschi F, Dondi D, Serra A, Profumo A, et al. Swine sewage as sacrificial biomass for photocatalytic hydrogen gas production : Explorative study. Int J Hydrogen Energy 2014;39:11433-40. doi:10.1016/j.ijhydene.2014.05.168.

[33] Chong R, Li J, Ma Y, Zhang B, Han H, Li C. Selective conversion of aqueous glucose to value-added sugar aldose on TiO2 -based photocatalysts. J Catal 
2014;314:101-8. doi:10.1016/j.jcat.2014.03.009.

[34] Jaswal R, Shende R, Nan W, Shende A. Photocatalytic reforming of pinewood ( Pinus ponderosa ) acid hydrolysate for hydrogen generation. Int $\mathrm{J}$ Hydrogen Energy 2017;42:2839-48. doi:10.1016/j.ijhydene.2016.12.006.

[35] Zou J, Zhang G, Xu X. One-pot photoreforming of cellulosic biomass waste to hydrogen by merging photocatalysis with acid hydrolysis. Appl Catal A, Gen 2018;563:73-9. doi:10.1016/j.apcata.2018.06.030.

[36] Payormhorm J, Chuangchote S, Kiatkittipong K, Chiarakorn S, Laosiripojana N. Xylitol and gluconic acid productions via photocatalytic-glucose conversion using TiO2 fabricated by surfactant-assisted techniques : Effects of structural and textural properties. Mater Chem Phys 2017;196:29-36. doi:10.1016/j.matchemphys.2017.03.058.

[37] Compagnoni M, Ramis G, Freyria FS, Armandi M, Bonelli B, Rossetti I. Innovative photoreactors for unconventional photocatalytic processes: the photoreduction of CO2 and the photo-oxidation of ammonia. Rend Lincei 2017;28. doi:10.1007/s12210-017-0617-z.

[38] Galli F, Compagnoni M, Vitali D, Pirola C, Bianchi CL, Villa A, et al. CO2 photoreduction at high pressure to both gas and liquid products over titanium dioxide. Appl Catal B Environ 2017;200:386-91. doi:10.1016/j.apcatb.2016.07.038.

[39] Rossetti I, Villa A, Pirola C, Prati L, Ramis G. A novel high-pressure photoreactor for CO2 photoconversion to fuels. RSC Adv 2014;4:28883-5. doi:10.1039/c4ra03751k.

[40] Olivo A, Ghedini E, Signoretto M, Compagnoni M, Rossetti I. Liquid vs. gas phase $\mathrm{CO} 2$ photoreduction process: which is the effect of the reaction medium? Energies 2017;10:1394. doi:10.3390/en10091394.

[41] Rossetti I, Villa A, Compagnoni M, Prati L, Ramis G, Pirola C, et al. CO2 photoconversion to fuels under high pressure: effect of TiO2 phase and of 
unconventional reaction conditions. Catal Sci Technol 2015;5:4481-7. doi:10.1039/C5CY00756A.

[42] Bahdori E, Tripodi A, Villa A, Pirola C, Prati L, Ramis G, et al. High pressure CO2 photoreduction using $\mathrm{Au} / \mathrm{TiO}$ : unravelling the effect of the co-catalyst and of the titania polymorph. Catal Sci Technol 2019;9:2253-65.

[43] Rossetti I, Bahadori E, Tripodi A, Ramis G. Modelling of Photoreactors for Water Treatment. Chem Eng Trans 2019;74:289-94. doi:10.3303/CET1974049.

[44] Ramis G, Bahadori E, Rossetti I. Photoreactors design for hydrogen production. Chem Eng Trans 2019;74:481-6. doi:10.3303/CET1974081.

[45] Bahadori E, Compagnoni M, Tripodi A, Freyria F, Armandi M, Bonelli B, et al. Photoreduction of nitrates from waste and drinking water. Mater Today Proc 2018;5:17404-13.

[46] Serpone N, Lawless D, Khairutdinov R. Size Effects on the Photophysical Properties of Colloidal Anatase TiO2 Particles: Size Quantization versus Direct Transitions in This Indirect Semiconductor? J Phys Chem 1995. doi:10.1021/j100045a026.

[47] Ribao P, Alexandra Esteves M, Fernandes VR, Rivero MJ, Rangel CM, Ortiz I. Challenges arising from the use of $\mathrm{TiO} 2 / \mathrm{rGO} / \mathrm{Pt}$ photocatalysts to produce hydrogen from crude glycerol compared to synthetic glycerol. Int J Hydrogen Energy 2018:113. doi:10.1016/j.ijhydene.2018.09.148.

[48] Ribao P, Alexandra Esteves M, Fernandes VR, Rivero MJ, Rangel CM, Ortiz I. Challenges arising from the use of TiO2/rGO/Pt photocatalysts to produce hydrogen from crude glycerol compared to synthetic glycerol. Int J Hydrogen Energy 2019;44:28494-506. doi:10.1016/j.jijhydene.2018.09.148.

[49] Petrosyan H, Vanyan L, Trchounian A, Trchounian K. Defining the roles of the hydrogenase 3 and 4 subunits in hydrogen production during glucose fermentation: A new model of a H2-producing hydrogenase complex. Int J Hydrogen Energy 2019. 
doi:10.1016/j.ijhydene.2019.09.204.

[50] Trchounian K, Trchounian A. Hydrogen producing activity by Escherichia coli hydrogenase 4 (hyf) depends on glucose concentration. Int J Hydrogen Energy 2014;39:16914-8. doi:10.1016/j.jijhydene.2014.08.059.

[51] Varas-concha F, Guzmàn D, Isaacs M, Navarrete C. Operational conditions affecting hydrogen production by the photoreforming of organic compounds using titania nanoparticles with gold. Energy Technol 2018;6:416-31.

doi:10.1002/ente.201700546.

[52] Carraro G, Maccato C, Gasparotto A, Montini T, Turner S, Lebedev OI, et al. Enhanced hydrogen production by photoreforming of renewable oxygenates through nanostructured Fe2O3 polymorphs. Adv Funct Mater 2014;24:372-8. doi:10.1002/adfm.201302043.

[53] Uddin T, Nicolas Y, Olivier C, Jaegermann W, Rockstroh N, Junge H, et al. Band alignment investigations of heterostructure $\mathrm{NiO} / \mathrm{TiO} 2$ nanomaterials used as efficient heterojunction earth-abundant metal oxide photocatalysts for hydrogen production. Phys Chem Chem Phys 2017;19:19279-88. doi:10.1039/c7cp01300k.

[54] Segovia-guzmán MO, Román-aguirre M, Verde-gomez JY, Collins-martínez VH, Zaragoza-galán G, Ramos-sánchez VH. Green Cu2O / TiO2 heterojunction for glycerol photoreforming. Catal Today 2018. doi:10.1016/j.cattod.2018.05.031.

[55] Wang C, Cai X, Chen Y, Cheng Z, Luo X, Mo S, et al. Efficient hydrogen production from glycerol photoreforming over Ag 2 O-TiO 2 synthesized by a sol-gel method. Int J Hydrogen Energy 2017;42:17063-74. doi:10.1016/j.ijhydene.2017.05.183.

[56] Fu X, Long J, Wang X, Leung DYC, Ding Z, Wu L, et al. Photocatalytic reforming of biomass: A systematic study of hydrogen evolution from glucose solution. Int $\mathrm{J}$ Hydrogen Energy 2008. doi:10.1016/j.ijhydene.2008.07.068.

[57] Lee S-K, Mills A. Platinum and palladium in semiconductor photocatalytic systems. 
Platin Met Rev 2003;47:61-72.

[58] Hope GA, Bard AJ. Platinum/titanium dioxide (rutile) interface. Formation of ohmic and rectifying junctions. J Phys Chem 1983. doi:10.1021/j100234a029.

[59] Michaelson HB. The work function of the elements and its periodicity. J Appl Phys J Appl Phys J Chem Phys II Explan Its Funct J Appl Phys Work Funct J Chem Phys Work Funct Elem J Appl Phys 1977. doi:10.1063/1.1699702.

[60] Wang P, Huang B, Dai Y, Whangbo MH. Plasmonic photocatalysts: Harvesting visible light with noble metal nanoparticles. Phys Chem Chem Phys 2012. doi:10.1039/c2cp40823f.

[61] Mustafa DE, Yang T, Xuan Z, Chen S, Tu H, Zhang A. Surface Plasmon Coupling Effect of Gold Nanoparticles with Different Shape and Size on Conventional Surface Plasmon Resonance Signal. Plasmonics 2010. doi:10.1007/s11468-010-9141-z.

[62] Bamwenda GR, Tsubota S, Nakamura T, Haruta M. Photoassisted hydrogen production from a water-ethanol solution: a comparison of activities of AuTiO2and PtTiO2. J Photochem Photobiol A Chem 1995. doi:10.1016/1010-6030(95)04039-I.

[63] Zhang X, Chen YL, Liu RS, Tsai DP. Plasmonic photocatalysis. Reports Prog Phys 2013;76. doi:10.1088/0034-4885/76/4/046401. 